\title{
Maré Rosa E Agenda de políticas sociais: AS PLATAFORMAS DE GOVERNO DO PSCh (2000) E PT (2002)
}

\author{
Beatriz de Paula Silva RIBAS*
}

RESUMO: O propósito deste artigo é analisar a agenda social das plataformas de governo de dois partidos de esquerda latino-americanos: o Partido Socialista do Chile (PSCh) no Chile e o Partido dos Trabalhadores (PT) no Brasil. Ambos os partidos participaram do fenômeno político notadamente conhecido como maré rosa, tido como a renovação e vitória eleitoral dos governos de esquerda ao poder executivo na América Latina. Esta análise parte da seguinte questão: Como são delimitadas as políticas sociais nos programas de governo do PSCh (2000) e do PT (2002)? Utilizaremos a análise de conteúdo para verificar quais as similaridades e as diferenças entre as duas plataformas e levantar inferências sobre o sistema de proteção social nos dois países, considerando o período em questão. Partiremos da hipótese de que estes partidos se apresentaram como alternativas para a crise de representação democrática e de legitimidade de partidos e sistemas partidários em vários países na denominada década perdida. Estas partes propuseram uma solução para o problema: ampliar as políticas sociais aplicadas a grupos sociais específicos, levando em consideração a heterogeneidade institucional e a política dos grupos de interesse.

PALAVRAS-ChAVE: Programa de Governo. Políticas Sociais. PT. PSCh. Maré Rosa.

\section{Introdução}

A estratégia de influência e liderança do público pelo presidente é avaliada sob várias perspectivas na Ciência Política. Uma questão-chave nesta temática

UFMG - Universidade Federal de Minas Gerais. Faculdade de Filosofia e Ciências Humanas. Programa de Pós-graduação em Ciência Política. Belo Horizonte - MG - Brasil. 31270-901 - beatrizribascp@ gmail.com. 
consiste na liderança da opinião pública (ERIKSON; MACKUEN; STIMSON, 2002). Muitos pesquisadores esforçam-se em compreender este fenômeno a partir da definição da agenda política, por considerarem que esta fase pode influenciar a opinião dos eleitores quanto às demandas que consideram mais relevantes. Nesse sentido, pressupõe-se que, se o presidente conseguir delimitar sua agenda de governo de maneira que atenda ao que é esperado pelo público, presume-se que ele seja bem avaliado. Tal estratégia é considerada um aspecto relevante para a aprovação presidencial. Uma possível explicação para isso é que os eleitores tendem a associar o desempenho das instituições políticas à imagem do chefe do Executivo. Por essa razão, uma agenda política bem delimitada é imprescindível.

Em meados dos anos 2000, as esquerdas latino-americanas começaram a ampliar a sua representatividade eleitoral, após um período difícil, marcado pela redução das suas bases sociais, que resultou numa crise geral, a qual interferiu, sobretudo, na organização desses partidos. Somado a isso, entre as décadas de 1980 e 1990, o colapso do socialismo real, que também influenciou para a crise do mais expoente campo teórico das esquerdas, o pensamento marxista, acentuou a situação. Como consequência, presenciou-se um contexto generalizado de instabilidade política. Frente à nova configuração econômica, social e política na América Latina, alguns partidos de esquerda apresentaram-se como alternativas aos partidos que estavam no poder, uma vez que colocaram no centro de sua agenda política a questão da representação democrática e passaram a criticar os fracassos do desenvolvimento democrático até então (SILVA, 2011). Para Serna (2004, p. 21), o que caracterizou as novas esquerdas foi um processo de "reconversão ideológica das identidades das esquerdas", as quais priorizaram a questão democrática e revalorizaram a prática política em seu discurso, além de defender uma forte agenda de políticas públicas.

Como consequência, as últimas décadas do século XX, criaram um contexto favorável à ascensão de tais partidos, que se deu de forma predominante e linear, cronologicamente na América Latina, em países como: Venezuela, Brasil, Argentina, Uruguai, Bolívia, Nicarágua, Equador, Paraguai, El Salvador e Costa Rica. Iniciouse, então, na década de 1990 , o fenômeno conhecido como maré rosa ${ }^{2}$ latinoamericana. A descrição deste acontecimento político nos interessará em virtude do

\footnotetext{
1 Para o autor, houve quatro meios de conversão ideológica, quais sejam, "o caminho republicano, a via social-democrata, a reinvenção nacional do socialismo e as correntes de democracia radical" (SERNA, 2004, p.21).

2 A terminologia "maré rosa" foi empregada por Panizza (2006) para se referir à ascensão dos partidos de esquerda na América Latina. A expressão tem como influência um fenômeno similar ocorrido na Europa, na segunda metade dos anos 90, denominado de "Onda Rosa", em que governos mais conservadores estavam sendo sucedidos por governos de centro-esquerda, com viés socialdemocrata. Segundo, Wanderley Júnior (2017, p. 18): "a opção pela nuance cor-de-rosa demonstra uma versão mais moderada do vermelho associado ao comunismo".
} 


\section{Maré Rosa e agenda de politicas sociais: as plataformas de governo do PSCh (2000) e PT (2002)}

nosso objetivo em avaliar, a partir dos planos de governo desse período, como as políticas sociais são abordadas em tais documentos. Neste caso, nos limitaremos a dois partidos desse espectro político que primeiramente chegaram ao governo central: o Partido Socialista do Chile (PSCh) no Chile e o Partido dos Trabalhadores (PT) no Brasil.

Entendemos relevante analisar a abordagem da área social nas plataformas de governo, tendo em vista as significativas mudanças que marcaram o sistema de proteção social na América Latina a partir das décadas de 1980 e 1990, sobretudo. Antes, tal sistema pautava-se primordialmente em direitos previdenciários. Apesar dessa importância social, assistia apenas uma parte da população, especificamente as pessoas inseridas no mercado de trabalho formal. Segundo Barrientos (2008), as mudanças provenientes da interação entre mercado e relações de trabalho podem ser vistas como facilitadores para a coexistência de regimes de bem-estar na região. Ou seja, para a caracterização de outros tipos de welfare que transpassam a clássica tipologia proposta por Esping-Andersen $(2013,1999)$, a qual define três tipos de estados de bem-estar: liberal, conservador e socialdemocrata. Ainda são recentes os estudos dedicados à análise do welfare state em países emergentes, por isso esperamos verificar as propostas de políticas de bem-estar social do Brasil e do Chile no momento de mudança do espectro político, numa conversão de vitórias eleitorais de direita à esquerda.

Este artigo divide-se em cinco tópicos, para além da introdução e conclusão. No primeiro, aborda-se a classificação dos regimes de bem-estar social no contexto latino-americano. No segundo, apresenta-se a evolução dos indicadores das despesas públicas na região a fim de contextualizar a influência das novas esquerdas na reorientação dos gastos sociais, sobretudo a partir do final dos anos 90. No terceiro tópico, apresenta-se uma breve retrospectiva histórica dos partidos que ascenderam ao poder central nos países da América Latina, tendo por base o fenômeno definido como maré rosa. No quarto, debate-se como temas sociais recebem atenção dos decisores políticos e, por conseguinte, são incorporados aos programas de governo. E, por fim, no quinto tópico, realiza-se uma análise dos programas de governo do PT e PSCh, voltando-se especificamente para os temas sociais para compreender como se caracterizam os sistemas de proteção social do Brasil e Chile.

\section{Caracterização dos regimes de Bem-Estar na América Latina}

Neste tópico, apresentaremos algumas considerações feitas a partir da literatura sobre estado de bem-estar social a fim de compreendermos aspectos apontados como relevantes e típicos do welfare state na América Latina e, 
consequentemente, entendermos o contexto em que a agenda social das esquerdas foi formada. Após 1990, período de ascensão das esquerdas ao Executivo, as instituições sociais responsáveis pela promoção do bem-estar passaram a ter mais proeminência nas pesquisas sobre políticas públicas, sobretudo no que diz respeito à miséria (DEL VALLE, 2010). O atual design institucional das políticas sociais faz parte de um sistema contemporâneo de proteção social que tem o objetivo de minimizar os problemas socioeconômicos provocados pelo mercado. Nesse sentido, o Estado assume a responsabilidade de garantir o bem-estar social de todos mediante a implementação de um modelo de Welfare State, ou seja, um modelo no qual a "intervenção pública destina[-se] a compensar ou reduzir as desigualdades socioeconômicas entre os cidadãos" (KERSTENETZKY, 2011, p.87). Entendemos que esta visão se associa à estrutura socioeconômica das sociedades modernas, tendo em vista que a percepção de welfare state pode estar relacionada a valores, juízos, aspectos ideológicos, dentre outros (WILENSKY, 1975).

A clássica tipologia dos regimes de bem-estar formulada por EspingAndersen (1991) foi bastante utilizada para a caracterização dos sistemas dos países membros da Organização para a Cooperação e Desenvolvimento Econômico (OCDE), ou seja, países industrializados. Nesse sentido, o desenvolvimento do Estado de bem-estar social pode ser estudado a partir da tríade: liberal, conservadora e socialdemocrata, as quais possuem características e efeitos distintos para o desenvolvimento do welfare state. Resumidamente, o welfare state liberal promove assistência aos mais pobres, porém a situação de vulnerabilidade social deve ser devidamente comprovada; ademais, o mercado tem um papel privilegiado na organização da economia e da vida social. $\mathrm{O}$ welfare conservador confere lugar de destaque ao corporativismo ou à família, pois considera estas formas de organização contraposições fundamentais ao individualismo resultante do mercado. Orienta-se pela necessidade das classes mais privilegiadas em cumprir determinadas responsabilidades sociais, como a ajuda assistencial. Por fim, o modelo de welfare state socialdemocrata visa à redução das desigualdades mediante políticas de caráter universal e que desmercantilizem o trabalho. Para tanto, busca conciliar o trabalho e o serviço de assistência social, além de promover a independência dos indivíduos (ressaltam-se aqui as questões de gênero quanto à inserção da mulher no mercado de trabalho).

Para o contexto dos países latino-americanos, os quais tiveram um processo de modernização mais tardio do que os países da OCDE, estudiosos concluem que esta classificação clássica de Esping-Andersen não abarca as diferenças e as particularidades desta região, sendo, portanto, necessário abranger, por exemplo aspectos histórico-culturais, econômicos e políticos, etc. (DEL VALLE, 2010). Os países considerados pioneiros no que diz respeito à implementação 


\section{Maré Rosa e agenda de políticas sociais: as plataformas de governo do PSCh (2000) e PT (2002)}

de seguros sociais na região são Argentina, Brasil, Chile, Costa Rica, Cuba e Uruguai (MESA-LAGO, 1989 apud DEL VALLE, 2010). Tais países possuem sistemas mais abrangentes, porém ainda enfrentam bastante estratificação social. A classificação de Mesa-Lago (1989) organiza os países a partir da criação e da expansão da cobertura de proteção social (alto, intermediário e baixo). Filgueira (2005), entendendo a necessidade de uma nova tipologia que abarcasse de maneira mais precisa a realidade da América Latina, divide os países entre regimes universalistas, dualistas e excludentes, tendo por base a heterogeneidade étnicocultural, o caráter regressivo ou progressivo dos sistemas de proteção social e o nível de informalidade nos mercados de trabalho.

Barrientos (2008) afirmar ter havido na América Latina a passagem de um modelo conservador-informal para um modelo liberal-informal. O primeiro compartilhava muitas características com o regime conservador definido por EspingAndersen (1991). Nesse caso, a proteção social derivava de um sistema estratificado de seguridade social destinado a atender trabalhadores formais. Para aqueles que não estavam inseridos no mercado, a família consistia na principal instituição responsável por amenizar os riscos sociais. Quanto ao modelo liberal-informal, esta combinação é resultante da nova conjuntura em que os riscos, antes compartilhados por todos, passaram, cada vez mais, a fazer parte da esfera individual, além de apresentarem natureza diversa. Essas e outras características tornam evidente a segmentação da produção de bem-estar na América Latina. Por esse motivo, não podemos falar de um welfare uno (liberal ou conservador, ou socialdemocrata). Todavia, uma importante ressalva deve ser feita à conclusão de Barrientos (2008): assim como não podemos observar a América Latina sob uma única classificação de welfare, também não podemos desconsiderar que esta é uma região bastante heterogênea, em que os países, sob muitos aspectos, destoam uns dos outros. Esta observação se deve à possibilidade de países — caracterizados pela heterogeneidade política e institucional — apresentarem indicadores distintos quanto ao estado de bem-estar social.

Sátyro e Cunha (2015) confirmam esta hipótese quando, ao empreender uma análise em perspectiva comparada sobre o caso dos municípios brasileiros, identificam seis tipos de welfare state (assistência social, semi-assistencial social, corporativo, semi-corporativo, seguro-família e regimes intermediários de bemestar). Esta multiplicidade de regimes deve-se à distribuição não aleatória de variáveis como pobreza, limitação do papel do estado, a ausência de mercado, a estrutura familiar e as redes alternativas de apoio social (SÁTYRO e CUNHHA, 2015). Portanto, segundo os autores, esta distribuição teria como consequência um padrão distinto de prestação de serviços de assistência social, incorrendo em modelos de bem-estar social distintos, inclusive em um mesmo país. 


\section{A reorientação do gasto social a partir de 1990: o contexto de ascensão das esquerdas na América Latina}

Os sistemas de proteção social da América Latina passaram por algumas mudanças a partir da década de 1980, tornando mais evidente a variação entre os países quanto aos gastos e à expansão da cobertura social. Mais precisamente a partir do final da década de 90, a região registrou uma redução progressiva dos indicadores de pobreza, o que se deve, em parte, ao aumento do gasto público nas áreas sociais. Novas políticas foram implementadas com a finalidade de reduzir as desigualdades decorrentes da má distribuição de renda. Apesar de ainda haver bastante desigualdade na região, fontes como Panorama Social, organizado pela Comissão Econômica para a América Latina e o Caribe (CEPAL, 2016), têm demonstrado evidências de que este característico cenário de distribuição de renda na região está melhorando ao longo dos anos. Vejamos:

Gráfico 1 - América Latina e Caribe (21 países): evolução e participação das despesas sociais públicas nas despesas totais de 1990-1991 a 2012-2013

(Percentagens do PIB e despesa pública total)

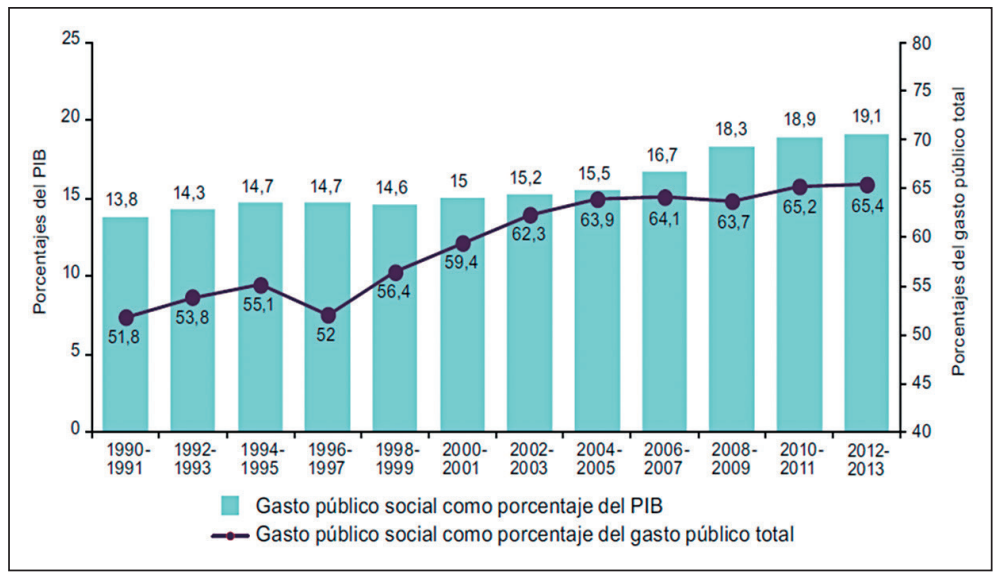

Fonte: Comissão Econômica para a América Latina e o Caribe (CEPAL), banco de dados de despesas sociais.

Houve, portanto, uma reorientação do gasto público total, sobretudo na década de 90, que já registrava um crescimento de 50\% no período de 1992 a 1993. Aumentou para $60,5 \%$ durante os anos de $2000-2001$ e chegou a $65,9 \%$ entre os anos de 2010 e 2011. Dado que o gasto público subsume os gastos sociais, devemos ter em conta que a ampliação deste incorreu no crescimento daquele. Ademais, neste período, os serviços públicos tiveram prioridade (CEPAL, 2016). A diminuição 


\section{Maré Rosa e agenda de políticas sociais: \\ as plataformas de governo do PSCh (2000) e PT (2002)}

da pobreza verificada no contexto latino-americano, como assinala o professor e pesquisador Lauro Mattei (2010), não pode ser associada apenas:

aos aspectos do crescimento econômico, uma vez que diversas políticas de Estado foram adotadas visando reduzir o problema. Assim, do ponto de vista das iniciativas governamentais, registre-se que os anos 1990 aportaram à região um conjunto de mudanças de ordem política e econômica destinadas à promoção da justiça social no Continente. Na esfera social procurou-se combater o problema da pobreza pela ótica liberal que prevaleceu no cenário mundial, o que induziu à implementação de políticas focalizadas, muitas das quais com caráter meramente compensatório (MATTEI, 2010, p. 20).

Dentre os fatores que contribuíram para reversão de tal situação estão os esforços governamentais para a implementação de políticas sociais, sobretudo as de redistribuição de renda. O propósito destas políticas é minimizar a situação de pobreza de parte da população, embora, em muitos casos, não tenham impacto significativo sobre a concentração de renda propriamente dita. Todavia ainda são evidentes as diferenças entre os países da América Latina. De acordo com o Relatório Pánorama Social (CEPAL, 2016), estas distinções correspondem tanto à quantidade de recursos destinados às áreas sociais quanto ao peso do orçamento público no PIB nas questões sociais. Dessa maneira, a capacidade de cada país de alocar recursos depende de fatores econômicos, políticos e sociais. A respeito disso, são muitos os estudos que enfatizam o papel das novas esquerdas latino-americanas para a melhoria dos indicadores (SANT'ANNA; SILVA, 2008, OLIVEIRA, 2009).

\section{Trajetória histórica da renovação das esquerdas na América Latina no final do século $X X$}

Para fins de precisão conceitual, define-se por esquerda toda forma de organização política - partidos, movimentos sociais ou associações políticas em geral - cujo programa de intervenção política tenha como objetivo programático a reivindicação - revolucionária ou reformista - de uma redução ou supressão das desigualdades sociais, isto é, a redução ou supressão das diferenças entre as classes sociais. O que irá distinguir a esquerda reformista da esquerda revolucionária é a estratégia utilizada por ambas na consecução deste mesmo fim. Por outro lado, também é comum a ambas as esquerdas a recusa do modelo individualista liberal, isto é, a recusa de uma economia de mercado em favor de uma economia de Estado com fins substantivamente (e não apenas formalmente) igualitários. 
Historicamente, a agenda política das esquerdas europeias obteve sucesso eleitoral quando decidiu abrir mão de propostas radicais e revolucionárias em favor de um programa reformista com vistas à consolidação de direitos sociais. Esse trade-off eleitoral, como o denominaram Przeworski, Manin e Stokes (1999), conduziu as esquerdas a aceitar as regras da competição política democrática e, assim, apresentar-se como uma alternativa de governo, isto é, apresentar-se como um conjunto de partidos políticos regulares, institucionais e portadores de uma plataforma pública de governo. No caso das esquerdas latino-americanas, o trade-off ocorreu tardiamente e de forma peculiar, tendo em vista que desde a fundação do Foro de São Paulo ${ }^{3}$ em 1990, a agenda reformista tem sido concebida como um estágio preliminar e estratégico para a implantação de uma agenda revolucionária. Quer dizer, enquanto para as esquerdas europeias ocidentais a aceitação das regras da competição democrática representou uma etapa final de sua trajetória política, para as esquerdas latino-americanas, tal aceitação representou tão-somente a etapa preliminar para a implantação de um novo socialismo. Portanto, desde o início dos anos 1990, a esquerda latino-americana passou a organizar-se de forma sistêmica e orquestrada, substituindo as estratégias revolucionárias e paramilitares dos anos 1960 pela estratégia da ascensão ao poder mediante a competição democráticopartidária. Como consequência, houve uma crescente ascensão dos partidos e líderes da esquerda aos governos nacionais após a adoção ou reformulação de estratégias viáveis que favorecessem a vitória no processo eleitoral. Este fenômeno de renovação das esquerdas é denominado de maré rosa ${ }^{4}$.

Os partidos desse espectro político alcançaram uma hegemonia historicamente inédita na América Latina. Em 1999, a eleição de Hugo Chávez, candidato do partido Movimento V República (MVR) na Venezuela, marcou o começo da chegada das esquerdas contemporâneas aos governos nacionais. Em 2000, no Chile, houve a vitória eleitoral de Ricardo Lagos, representante do Partido Socialista do Chile (PSCh). No Brasil, Luiz Inácio Lula da Silva, candidato do Partido dos Trabalhadores (PT) foi eleito presidente em 2002. No ano seguinte, em 2003, Néstor Kirchner, do Partido Judicialista (PJ), venceu as eleições na Argentina. No Uruguai, Tabaré Vásquez, se elegeu em 2004, pelo partido Frente Ampla (FA). Na Bolívia, em 2005, Evo Morales foi eleito presidente pelo partido Movimento ao Socialismo (MAS). Em 2006, no Equador, Rafael Correa venceu as eleições, representando o partido

3 O Foro de São Paulo designa o grupo das organizações, dos partidos de esquerda e frentes de esquerda da América Latina e do Caribe, iniciado em 1990, em uma conferência convocada pelo Partido dos Trabalhadores (PT). O objetivo do primeiro encontro consistia em discutir os efeitos das políticas neoliberais amplamente implementadas na região e, por conseguinte, renovar os projetos de esquerda (DECLARAÇÃO FINAL DE SÃO PAULO, 1990). A partir de então, os encontros posteriores do Foro de São Paulo passaram ser realizados a cada um ou dois anos.

4 Lieveslay and Ludlam (2009), Gavarito, Barret e Chavez (2005), Natason, 2008 (apud Silva, 2011). 


\section{Maré Rosa e agenda de políticas sociais: as plataformas de governo do PSCh (2000) e PT (2002)}

Pátria Altiva e Soberana (PAÍS). Também em 2006, na Nicarágua, Daniel Ortega foi eleito pela Frente Sandinista de Libertação Nacional (FSLN). Ainda no mesmo ano, Alan García venceu as eleições no Peru, pelo Partido Aprista Peruano (APRA). No Paraguai, em 2008, Fernando Lugo foi eleito pelo partido Alianza Patriótica para el Cambio (APC). No ano de 2009, Mauricio Funes foi nomeado presidente de El Salvador, representando o Partido Frente Farabundo Martí de Libertação Nacional (FMLN). E em 2014, Luis Guillermo Solís foi eleito presidente da Costa Rica, pelo Partido da Ação Cidadã (PAC).

Diante dessa cronologia, podemos afirmar que essas organizações políticas, sobretudo dos países em análise (Brasil e Chile), caracterizaram-se por um contexto sócio-histórico relativamente comum no qual chegaram ao poder central (tensão do socialismo real e do pensamento marxista, colapso do modelo nacionaldesenvolvimentismo, proeminência neoliberalismo, além de terem se tornado democracias recentes).

\section{A configuração da agenda-setting: processo de formulação e seleção de temas}

É de suma importância que o Estado promova a igualização de situações sociais desiguais. Mas, afinal, uma vez que somente a garantia constitucional de direitos não basta, como esta igualização pode ser feita na prática? Uma possibilidade consiste na implementação de políticas públicas, que representem respostas a problemas públicos, organizadas a partir de um aparato institucionallegal do Estado (SECCHI, 2015). Tais respostas, materializadas em políticas públicas, devem atender a determinados anseios da sociedade - inputs de demandas (RUA; ROMANINI, 2013).

A formulação de políticas públicas depende do fluxo entre demandas sociais (inputs externos) e demandas e apoios oriundos do sistema político correspondentes a seus atores (whithinputs). Apesar disso, é possível considerarmos uma relação de bitransitividade entre políticas públicas e a política em si. Em outras palavras, as policies podem não apenas influenciar, mas também, ser influenciadas pela polity, ou seja, pelo arranjo institucional e a dinâmica política (RUA; ROMANINI, 2013). É imprescindível, portanto, considerar o processo em que determinados problemas preocupam o governo e os formuladores de políticas públicas a ponto de compor a agenda governamental (agenda-setting) e requerer alternativas que os solucionem via política pública (CAPELLA, 2006).

A fim de compreendermos como se dá o processo de formulação de políticas públicas, enfatizaremos inicialmente o processo de definição da agenda 
governamental (agenda-setting). Essa discussão justifica-se porque há uma série de fatores que precedem a elaboração das políticas. A respeito disso, Kingdon (2003) elaborou um modelo nomeado de Múltiplos Fluxos ${ }^{5}$ (Multiples Streams). O seu objetivo principal consistia em saber porque alguns problemas chamam a atenção do governo a ponto de comporem a agenda governamental. Ou seja, a pesquisa consistiu em verificar porque determinados assuntos chamam mais atenção dos decisores políticos do que outros. A seu ver, "nós sabemos mais sobre como as questões são descartadas do que sabemos sobre como elas vieram a ser questões da agenda governamental" (KINGDON, 2003, p.1).

Segundo Kingdon (2003), nem toda situação ou questão social percebida tem uma resposta por parte do Estado. Porém um conjunto de fatores, tais como: eventos, crises, símbolos e feedback das ações governamentais, podem fazer com que determinadas questões passem a ser, de fato, consideradas problemas. Este é então o primeiro fluxo (problem stream). Capella (2006) afirma que o grande volume de decisões e a incapacidade de propor alternativas a todas as questões que se apresentam aos formuladores políticos os levam a decidir, mediante esses fatores, quais situações devem ter uma solução via política pública. Tem-se, portanto, o segundo fluxo (policy stream). As policy communities, formadas por especialistas, são responsáveis por difundir as ideais acerca de possíveis soluções para problemas. Com isso, as ideias se confrontam, concorrem entre si, e as que têm continuidade no processo são aquelas consideradas mais viáveis tecnicamente, menos custosas, ou ainda, que contam com o apoio público e dos formuladores. A interação entre os atores participantes desse processo pré-decisório baseia-se no jogo do convencimento (soften up). Assim, há um processo de seleção, no qual predominam aquelas alternativas que alcançam o maior número de adeptos.

O terceiro fluxo é o político (politcs stream), caracterizado pelo processo de barganha e transações políticas. É composto de fatores como oscilações do humor nacional, resultados das eleições, mudanças de administração, mudanças de distribuições ideológicas ou partidárias no Congresso e campanhas de pressão de grupos de interesse. Em um governo, o volume de negócios tem poderosos efeitos nas agendas. Uma mudança de administração, a negociação dos assentos do Congresso, ou uma mudança de pessoal superior em uma agência administrativa, podem alterar substancialmente as agendas. (KINGDON, 2003).

Capella (2006, p. 30) explica que: "Grupos de pressão, a opinião pública, as pressões do Legislativo e das agências administrativas, os movimentos sociais, o processo eleitoral, entre outros fatores, determinam o clima político para a mudança da agenda governamental, podendo tanto favorecer uma mudança, como restringi-la".

\footnotetext{
5 A pesquisa de Kingdon (2003) baseou-se a análise de duas políticas específicas dos Estados Unidos: a de saúde e transporte.
} 


\section{Maré Rosa e agenda de politicas sociais: as plataformas de governo do PSCh (2000) e PT (2002)}

O processo decisório de uma política pública é, portanto, bastante complexo. São muitos os fatores intervenientes e, obviamente, o desenho institucional é determinante. Estas considerações sobre o processo de formulação da agenda de governo fizeram-se importante para que, no tópico seguinte, possamos observar a maneira como as políticas sociais são apresentadas nos programas de governo e quais as principais áreas sociais consideradas.

\section{Análise da agenda social dos Programas de governo: PT e PSCh}

\section{a. Programa de Governo 2002 - Coligação Lula Presidente: Um Brasil Para Todos}

O conteúdo do programa Um Brasil Para Todos elaborado para a eleição de 2002 é considerado um documento mais pragmático em relação aos programas de governo das competições eleitorais passadas (Brasil urgente: Lula presidente, de 1989; Lula presidente: uma revolução democrática no Brasil, de 1994; União do povo: muda Brasil, de 1998), ao todo possui 74 páginas. Os dois principais objetivos são o desenvolvimento econômico e a erradicação das desigualdades. Tais objetivos estruturam um projeto de estado de bem-estar social para o Brasil com contornos de um modelo socialdemocrata. O eixo a partir do qual todo o documento foi organizado é o social, considerado o único meio pelo qual seria viável:

A implantação de um modelo de desenvolvimento alternativo, que tem o social por eixo, só poderá ter êxito se acompanhada da democratização do Estado e das relações sociais, da diminuição da dependência externa, assim como de um novo equilíbrio entre União, estados e municípios (PT, 2002, p. 2, grifo nosso).

Em torno das questões sociais, verifica-se, portanto, algumas palavras-chave, as quais são mencionadas ao longo do programa, sendo as principais: 1) social; 2) inclusão; 3) desigualdade; 4) igualdade; 5) justiça social; 5) cidadania; 6) políticas públicas. Todas estas questões só poderiam ser alcançadas ou solucionadas mediante um novo contrato social (PT, 2002). Por esse motivo, o programa apresenta a candidatura de Luiz Inácio Lula da Silva à presidência como a possibilidade de um modelo de desenvolvimento alternativo para o país. Este modelo pressupõe a atuação ativa e massiva do Estado frente ao mercado. Depreende-se, a partir do programa, que tal controle permitiria mais eficácia na implementação de políticas públicas, ou seja, garantiria a provisão de serviços públicos com mais qualidade. Recebem destaque as seguintes áreas sociais setoriais: saúde, educação, previdência social e habitação. 
Os princípios e projetos de políticas sociais para a área da educação são desenvolvidos em três tópicos específicos: 1) Educação e Cultura para Fortalecer a Coesão do País; 2) A política de Educação; e 3) Uma Nova Política Educacional ${ }^{6}$. Encontramos, de antemão, a afirmação de que esta é uma questão de "primeira importância". O programa de governo prevê o investimento na educação pública em todos os níveis de ensino (infantil, fundamental, ensino médio e ensino superior, salém do ensino profissionalizante). Tal investimento deveria ser progressivamente maior (PT, 2002, p.47). A plataforma petista entende que o governo vigente no país (Fernando Henrique Cardoso) desobrigou o Estado de suas responsabilidades com a educação, o que resultou em maciça privatização das instituições de ensino, principalmente no nível superior. A partir da crítica aos repasses de recursos feitos pela União e aos sistemas avaliativos da educação - a exemplo de provas como o Exame Nacional do Ensino Médio e do Exame Nacional de Cursos -, o programa de governo do PT propõe políticas educacionais mais sólidas que visassem à formação dos professores (qualificação, treinamento, etc.). Além disso, enfatiza a necessidade de remuneração mais elevada a esses profissionais e prevê a reformulação das grades curriculares escolares.

Ainda quanto à área da educação, a meta do governo consistiria na universalização da Educação Básica em um prazo de quatro anos. O acesso às creches também é tido como um dos objetivos e deveria ser universal. Para o nível médio, apresenta-se a ideia de uma política social para jovens trabalhadores, que contaria com a expansão do Fundo de Manutenção e Desenvolvimento do Ensino Fundamental e de Valorização do Magistério (Fundef). As políticas sociais deveriam ser formuladas e implementadas a partir da colaboração entre a União e as subunidades nacionais. É ressaltada também a participação da sociedade para a efetividade de tais políticas.

Quanto à política de saúde, estabelece-se que a Seguridade Social seria a base para a provisão dos serviços. Os direitos sociais, portanto, corresponderiam ao contexto em que a saúde seria organizada. A União, os estados, o Distrito Federal e os municípios seriam responsáveis pelo financiamento das políticas. So funcione de maneira efetiva: "oferecendo cooperação técnica e financeira para fortalecer estados e municípios para que, respeitando o controle social, exerçam a gestão descentralizada do SUS" (PT, 2002, p.49). É previsto ainda, segundo o programa de governo, novas medidas de monitoramento de metas e resultados as quais seriam mais eficientes que as do Ministério da Saúde do governo de Fernando Henrique Cardoso (FHC). Porém esta estratégia não é detalhada.

No que diz respeito à política de assistência social, há dois tópicos que mencionam como seria a política adotada pelo governo Lula, descrito como

6 PT, 2002, páginas: 14, 44 e 46, respectivamente. 


\section{Maré Rosa e agenda de políticas sociais: as plataformas de governo do PSCh (2000) e PT (2002)}

um governo que buscaria a universalização do acesso à saúde e a qualidade de serviços, desprezando quaisquer práticas clientelistas e tuteladas (PT, 2002). Os demais tópicos destinam críticas ao funcionamento da política vigente. Assim como na política educacional, as ONGs também poderiam ser complementares na efetividade das políticas de saúde. Os municípios e estados deveriam cooperar em sistema descentralizado e participativo. As principais instituições mencionadas no programa de governo são: Ministério da Saúde, Terceiro Setor, Organizações Não Governamentais (ONGs) e Conselhos de Saúde.

$\mathrm{Na}$ área de Infraestrutura e Desenvolvimento Sustentável, dispõe-se sobre políticas de médio e longo prazo com o objetivo de dirimir as desigualdades do país. A principal estratégia a ser adotada consistiria em medidas de distribuição de renda. Tais medidas deveriam levar em consideração as diversidades regionais e culturais. Recebem destaques o parque produtivo nacional, com ênfase na tentativa de recuperar a sua infraestrutura de produção. Para isso, o programa garante que o "governo manterá distância tanto do velho nacional-desenvolvimentismo das décadas de 1950, 1960 e 1970 quanto do novo liberalismo que marcou os anos 90" (PT, 2002, p.52). Segundo o projeto, seriam redefinidas as prioridades do Estado, tendo em vista uma gestão descentralizada. As políticas de infraestrutura abarcariam a construção de moradias (Projeto Moradia) e melhoria do saneamento básico, expansão da mobilidade urbana (com priorização do transporte público mediante uma política nacional de transporte), controle de impactos ambientais, planejamento energético, etc.

O programa de governo Um Brasil para Todos também discorre sobre a política de garantia de renda mínima, reafirmando o novo desenho desta política que passou a vigorar no país a partir da década de 1990, o qual priorizava uma renda mínima levando em consideração a família e a educação. No documento, há a previsão de revisão dos seguintes programas: Bolsa Escola, Bolsa Alimentação e o Programa de Erradicação do Trabalho Infantil (PETI). Programas sociais a nível municipal seriam criados para atender crianças, a partir de 0 anos, até adolescentes de 15 anos. Para a faixa etária entre 16 e 25 anos, seriam destinadas bolsas de estudos para jovens carentes mediante a contrapartida de serviços comunitários. Para adultos entre 22 e 50 anos, previam-se políticas de capacitação profissional, segurodesemprego para os trabalhadores formais e auxílio de renda para os informais. Além de tais políticas, seria adotado o programa Nova Oportunidade para os indivíduos entre 21 e 66 anos que estivessem desempregados. Há ainda a previsão de uma política para erradicar a forme do Brasil, chamada Projeto Fome Zero, o qual seria destinado às famílias pobres. As famílias receberiam um cartão com o qual fariam a compra de alimentos que lhes faltassem. Esta política contribuiria, para além do problema da fome, com a frequência e o rendimento escolar dos estudantes carentes. 
A plataforma de governo do PT, em 2002, defende uma repactuação federativa, a qual deveria conferir mais autonomia aos entes (União, Estados e Municípios). É constante no documento a reafirmação de urgência na solução ou redução das desigualdades, sejam de caráter social ou econômico, sem deixar à margem as diferenças regionais. Infere-se que a equalização social e econômica precede (e é quesito imprescindível) ao título de cidadania: "o combate às desigualdades econômicas e sociais é condição necessária para que seja garantido a todos os brasileiros e brasileiras o status de cidadãos, homens e mulheres realmente iguais perante a lei" (PT, 2002, p. 3). Reconhece-se que as injustiças distributivas da sociedade brasileira não se relacionam tão somente às questões de natureza econômica.

\section{b. Programa de Gobierno: Para Crecer Con Igualdad (2000)}

O programa de governo de Ricardo Lagos possui 28 páginas. O documento apresenta uma agenda política estruturada em torno de um conjunto vasto de temas, dentre eles: Igualdade, Crescimento econômico, Emprego, Educação, Ciência e tecnologia, Saúde, Gênero, Proteção às famílias, Direitos das crianças e jovens, adultos, Pessoas com deficiência, Meio ambiente, Cultura, Comunicação, Segurança, Descentralização, Participação, Democracia, Reforma do Estado, Justiça, Direitos humanos, Defesa nacional e Povos indígenas. Estas, portanto, são as palavras centrais que norteiam o programa. Apesar da multiplicidade temática, o objetivo central é o "progresso com igualdade". Nesse sentido, o país deveria se desenvolver priorizando o respeito a todas as pessoas, sem distinção:

A igualdade que estamos falando é a que procura criar oportunidades; a que permite a justiça social, a desconcentração econômica, política e territorial. É a que torna possível que os talentos dos membros de cada família chilena floresçam; a que é baseado em uma comunidade onde a colaboração e a confiança reina; aquela que disponibiliza a todos os instrumentos de progresso; que permite o pleno uso da liberdade (PSCh, 2000, p. 1, tradução nossa) ${ }^{7}$.

Na agenda de Ricardo Lagos, há a promessa de reforma do sistema de saúde, de renovação da educação, ampliação da proteção da família, segurança para os

7 Trecho original: "La igualdad de la que hablamos es la que busca crear oportunidades; la que permite la justicia social, la desconcentración económica, política y territorial. Es la que hace posible que florezcan los talentos de los miembros de cada familia chilena; la que se funda en una comunidad donde reinan la colaboración y la confianza; la que pone a disposición de cada uno las herramientas del progreso; la que permite el uso pleno de la libertad." 


\section{Maré Rosa e agenda de politicas sociais: as plataformas de governo do PSCh (2000) e PT (2002)}

indivíduos e à nação, inserção integral das mulheres, políticas para meio ambiente, humanização dos meios urbano, descentralização, liberdade cultural, priorização dos preceitos democráticos, empregabilidade, etc.

Quanto à educação, esta área é apresentada como prioridade do governo, por ser considerada a base primeira para a igualdade de oportunidade entre os indivíduos e para a superação da pobreza. Por isso, a agenda política prevê maior investimento para a educação das pessoas mais marginalizadas, em situação de vulnerabilidade. Um dos problemas a ser resolvidos seria a grande diferença existente entre os estabelecimentos de ensino em termos de recursos, pois enquanto alguns recebem mais recursos financeiros; outros têm contributo compartilhado e alguns nem possuem renda complementar. Nesse sentido, uma das medidas seria a adoção de bolsas de estudo para que assim os cidadãos pudessem acessar serviços públicos de mais qualidade e de maneira mais igualitária. Frisa-se a ampliação da cobertura da educação infantil, a exemplo das creches, como essencial às mães que precisam trabalhar. O programa prevê o atendimento alternativo às crianças de 2 a 5 anos, mas não esclarece que tipos de atendimento seriam esses.

A política educacional também pretende alcançar a universalização do ensino às crianças de 5 a 6 anos. Ademais, a educação também seria melhorada a partir de atividades de desenvolvimento físico, esporte e cultura. Para tanto, as escolas deveriam ser preparadas quanto à infraestrutura e aos recursos humanos e materiais. O governo de Ricardo Lagos objetiva também a expansão do ensino de uma segunda língua nas escolas, sobretudo, da língua indígena, além da reformulação dos currículos, mudança da carga-horária, etc. De acordo com o programa, a ampliação do aceso à rede de internet, a capacitação dos professores, a modernização das escolas e universidades e o sistema de financiamento estudantil também fariam parte da política educacional.

$\mathrm{Na}$ área da saúde, verifica-se a tentativa de desvencilhar os serviços de saúde como uma ação caritativa e torná-los deveres do Estado. Para isso, é prevista a extinção da exigência de cheques de garantia para que os cidadãos tenham assistência médica. Uma das propostas de governos é que os serviços fossem definidos a partir da Carta de Direitos e Deveres da Saúde. O governo de Ricardo Lagos se propõe a atuar em cinco setores: atenção primária, atenção de urgência, de especialistas, cirurgia e doenças graves. Para cada setor, há uma descrição sobre a equipe de especialistas, idade dos pacientes, tempo de espera para o atendimento ou início do tratamento, tempo para resultados dos exames, etc. Observa-se a tentativa de um sistema de saúde universalista:

Que as ações de saúde pública atinjam todos os chilenos, não importa onde eles vivam. Obtenha horas de atenção sem procedimentos em qualquer estabelecimento 
público, e que a referida citação seja respeitada. Receba atendimento de emergência durante as 21 horas do dia em qualquer Serviço de Emergência (PSCh, 2000, p.10, tradução nossa) ${ }^{8}$.

O programa de governo do PSCh trata de políticas sociais voltadas aos trabalhadores informais, mas prevê políticas assistenciais às famílias e às pessoas em situação de desemprego (PSCh, 2000). Há, por outro lado, um vasto conjunto de medidas voltadas ao crescimento econômico do país que se pauta essencialmente nos trabalhadores formais. A plataforma antevê políticas de proteção para as famílias voltadas para: as condições de trabalho, o apoio às famílias dos desempregados, o transporte, a saúde, a alimentação escolar, os benefícios de transferência de renda, as medidas de responsabilidades familiares compartilhadas entre homens e mulheres, proteção contra a violência doméstica (aprimoramento da Ley de Violencia Intrafamiliar), criação de centros de mediação de conflitos, dentre outras.

Grande destaque é dado às questões de gênero nesta plataforma, tendo em vista a proposição de políticas que incentivem e facilitem o acesso das mulheres ao mercado de trabalho. Dentre as propostas estão: o reforço às medidas de assistência infantil por meio da ampliação da cobertura dos dias escolares alternativos, construção de centros educacionais, creches, inclusive a criação de instituições voltadas aos cuidados de menores em horários não convencionais para que os pais possam trabalhar sem prejudicar o sustento e a educação dos filhos. Ademais, pretende-se aprimorar a legislação e o controle no que diz respeito ao trabalho das mulheres (contratos, salários, licença maternidade, casos de assédio, discriminação por sua condição feminina, etc.). Uma das medidas a serem adotadas segundo o programa, é uma lei que estabeleça a igualdade de remuneração para homens e mulheres. Além disso, seria definida uma política referente à compatibilidade da jornada de trabalho com a vida familiar, etc. Algumas das políticas já mencionadas correspondem também à segurança das crianças e jovens. Somam-se a estas, iniciativas com vistas à erradicação do trabalho infantil e à implementação de políticas de lazer.

Políticas sociais também seriam destinadas às pessoas com deficiência (mental, física, sensorial ou de causa psiquiátrica), no âmbito da saúde, da educação, do trabalho e previdência, da habitação e do planejamento urbano, da cultura e lazer. O Fondo Nacional de Descapacidad (FONADIS) receberia mais investimentos financeiros. Além disso, seriam firmados convênios que garantissem oportunidades às pessoas com deficiência. A área da segurança pública contaria:

8 Trecho orginal: "Que las acciones de salud pública lleguen a todos los chilenos, no importando donde vivan. Obtener hora de atención sin tramitaciones en cualquier establecimiento público, y que dicha citación sea respetada. Recibir atención de emergencia durante las 21 horas del día en cualquier Servicio de Urgencia". 


\section{Maré Rosa e agenda de politicas sociais: as plataformas de governo do PSCh (2000) e PT (2002)}

com um programa nacional que envolveria a atuação da comunidade, da polícia e dos municípios, programas de prevenção à criminalidade (na escola, no trabalho e na comunidade), criação de centros abertos, políticas de recuperação e melhoria dos espaços públicos, dentre outras medidas.

\section{Considerações Finais}

Neste artigo apresentamos como os programas de governo do Partido Socialista do Chile (2000) no Chile e do Partido dos Trabalhadores (2002) no Brasil definiram suas agendas de políticas sociais. A partir dos programas de governo, verifica-se ainda a pretensão de ampliar a cobertura de políticas sociais a grupos minoritários. Observando as propostas destinadas às políticas sociais da plataforma petista, constata-se uma tentativa de conferir mais proeminência a classes sociais minoritárias, caracterizadas por serem marginalizadas: mulheres, negros, índios, migrantes, portadores de deficiências e pessoas que possuam distintas orientações sexuais. Além desses grupos, há propostas para jovens, idosos e migrantes oriundos de regiões mais acometidas pela pobreza, crises, etc. São diversas as páginas que tratam desses grupos. Há uma grande preocupação com o grau de indigência e marginalização social, tendo em vista que a situação de bem-estar social durante este período era bastante agravada para aqueles não inseridos no mercado de trabalho. Mulheres, negros, jovens e migrantes estão entre os grupos menos protegidos do Brasil, inclui-se aí que são os mais expostos ao desemprego e aos riscos sociais.

No caso do programa Para Crecer Con Igualdad, os grupos marginalizados socialmente para os quais são estabelecidas as políticas são: as mulheres, a população indígena e as pessoas com deficiência. É importante frisar que, diferente da plataforma do PT, o PSCh confere pouca atenção aos problemas raciais enfrentados pelas pessoas negras. Este problema é tão somente relacionado aos indígenas, para os quais é proposto (de maneira não detalhada) um "novo quadro institucional político e jurídico da participação indígena na sociedade chilena e no respeito dos seus direitos" (PSCh, 2000, p. 28). Apesar da inexistência de políticas de anti-discriminação racial para outras parcelas da população, muitas propostas de políticas são definidas para dirimir a desigualdade de gênero. Nesse quesito, as mulheres recebem mais atenção quanto às políticas sociais no programa do partido chileno do que no brasileiro. Enquanto no programa de Lula, percebe-se que a questão do gênero é abordada de maneira tímida, a agenda de Ricardo Lagos se direciona, sobretudo, para a inserção e a permanência das mulheres no mercado de trabalho, com iniciativas relacionadas ao compartilhamento de responsabilidades 
familiares aos homens e mulheres, à compatibilidade da jornada de trabalho com a vida familiar, aos direitos parentais, à legislação sobre condições e à remuneração de trabalho, dentre outras.

O público-alvo das propostas políticas ainda são as pessoas e famílias em situação socioeconômica vulnerável. As políticas sociais propostas pelo programa Um Brasil para Todos possuem natureza mais familiarizante, enquanto o programa Para Crecer Con Igualdad propõe políticas desfamiliarizantes que incentivam e favorecem a participação da mulher no mercado de trabalho. Ressaltamos este aspecto porque a desfamiliarização das responsabilidades das mulheres é considerada uma condição para que elas se mercantilizem (ESPINGANDERSEN, 2013). A despeito disso, de maneira geral, ambos os documentos apresentam características progressistas e objetivam um sistema de proteção social universalista por meio de medidas que enfrentem o problema de acesso limitado aos serviços públicos. Aproximam-se, portanto, de um modelo de welfare state socialdemocrata, com a tentativa de ampliar as políticas sociais aplicadas a grupos sociais específicos.

\section{The Pink Tide and social policy agendas: the government PLATFORMS OF THE PSCH (2000) AND THE PT (2002)}

ABSTRACT: In this paper I propose an analysis of the social agenda of the government program of two Latin-American left-wing parties: the Socialist Party of Chile (PSCh) and the Workers' Party (PT) in Brazil. Both were part of the socalled "Maré Rosa" or Pink Tide, a political phenomenon which brought about an electoral renewal and the victory of left-wing parties in elections for the executive branch in Latin America. The starting point of my analysis is the question: what are the similarities and the differences in the social agendas of these two parties between the years 2000 and 2002? We hypothesize that both parties were elected amid a crisis of democratic representation and the loss of legitimacy of mainstream parties as well as the party system during the "lost decade". Both proposed a solution to this problem: augment social policies applicable to certain specific groups, taking into account the institutional and political heterogeneity of these interest groups.

KEYWORDS: Government Program. Social politics. PT. PSCh. Pink tide. 


\section{REFERÊNCIAS}

BARRIENTOS, Armando. Latin America: towards a liberal-informal welfare regime. In: GOUGH, Ian; WOOD, Geof (Org.). Insecurity and welfare regimes in Asia, Africa and Latin America: social policy in development contexts. Cambridge: University Press, 2008.

CAPELLA, Ana Cláudia. Perspectivas Teóricas sobre o Processo de Formulação de Políticas Públicas. Revista Brasileira de Informação Bibliográfica em Ciências Sociais (BIB). São Paulo, ANPOCS, nº 61, 2006, 25-52.

CEPAL, Nações Unidas. Panorama Social de América Latina 2015. Cepal, 2016.

DeClaraÇão final de SÃo PaUlO, 1990. Foro de São Paulo. Disponível em: < http://forodesaopaulo.org/declaracao-final-sao-paulo-1990/> Acesso em: 30 de mai. 2018.

DEL VALLE, Alejandro. Comparando regímenes de bienestar en América Latina. Revista Europea de Estudios Latinoamericanos y del Caribe, Amsterdã, p. 61-76, 2010.

ERIKSON, Robert S.; MACKUEN, Michael B.; STIMSON, Ames A. Public Opinion and Policy. In: MANZA, Jeff; PAGE, Fay Lomax (Org.) Navigating public opinion: Polls, policy, and the future of American. New York: Oxford University Press, 2002.

ESPING-ANDERSEN, Gøsta. The three worlds of welfare capitalism. Nova Jersey: John Wiley \& Sons, 2013.

. Social foundations of postindustrial economies. New York: Oxford University Press, 1999.

As três economias políticas do Welfare State. Lua Nova: Revista de Cultura e Política, São Paulo, 24, p. 85-116. 1991.

FILGUEIRA, Fernando. Welfare and democracy in Latin America: the development, crises and aftermath of universal, dual and exclusionary social states. Geneva: United Nations Research Institute for Social Development, 2005.

GARAVITO, César A. Rodríguez, BARRET, Patrick S., CHAVEZ, Daniel (Org.). La nueva izquierda en América Latina - sus orígenes y trayectoria futura. Bogotá: Norma, 2005.

JÚNIOR, Wanderley dos Reis Nascimento. A amplitude da maré rosa: uma análise das experiências de governo no Brasil, Chile e Uruguai. 2017. 184 f. Dissertação (Mestrado de Integração Contemporânea da América Latina) - Instituto Latino-Americano de Economia, Sociedade e Política, Universidade Federal da Integração Latino-Americana Foz do Iguaçu, 2017. 
KERSTENETZKY, Celia Lessa. Welfare state e desenvolvimento. Dados, Rio de Janeiro, v. 54, n. 1, p. 129-156, 2011.

KINGDON, J. W. Agendas, alternativas and public policies. New York: Longman, 2003.

LIEVESLAY, Geraldine; LUDLAM, Steve (Orgs). Reclaiming Latin America: experiments in radical social democracy. London, New York: Zeb Books Ltd, 2009.

MATTEI, Lauro. Notas sobre programas de transferência de renda na América Latina. Texto para discussão, n. 10. Instituto de Estudos Latino-Americanos. Universidade Federal de Santa Catarina, 2010.

MESA-LAGO, Carmelo. Ascent to Bankruptcy. Pittsburgh: University of Pittsburgh Press, 1989.

OLIVEIRA, Augusto Neftali Corte de. Partidos e política social no Brasil e no Chile: PT e PS nas eleições e no governo. Revista Debates, Porto Alegre, v. 3, n. 2, p. 39-67, 2009.

PANIZZA. Francisco. La marea rosa. Análise de Conjuntura OPSA, no 8 . Instituto Universitário de Pesquisas do Rio de Janeiro, Rio de Janeiro, 2006.

PARTIDO, Dos Trabalhadores. Programa de governo 2002 - Coligação Lula Presidente: Um Brasil para Todos. São Paulo, 2002.

PARTIDO, Socialista do Chile. Programa de Gobierno: Para Crecer Con Igualdad. Santiago de Chile: Concertación de Partidos por la Democracia, 2000.

PRZEWORSKI, Adam; MANIN, Bernard e STOKES, Susan. Elections and Representation. In: PRZEWORKI, A.; SOTKES, S. C.; MANIN, B. (Org.). Democracy, Accountability, and Representation. Cambridge: Cambridge University Press, 1999. p. 29-48.

RUA, Maria das Graças; ROMANINI, Roberta. Para Aprender Políticas Públicas: conceitos e teorias. Brasília: Instituto de Gestão Economia e Políticas Públicas, 2013.

SANT'ANNA, Julia; SILVA, Fabricio Pereira da. Esquerdas Latino-americanas e Gasto Social: Há Coerência entre Propostas e Práticas? Revista Debates, Porto Alegre, v. 2, n. 1, p. 150-178, jan. 2008.

SÁTYRO, Natália e CUNHA, Pedro. Why understanding social protection heterogeneity on the Brazilian municipalities matters? The coexistence of welfare regimes in a same country, a comparative analysis. ESPAnet Conference, Dinamarca, set. 2015.

SECCHI, Leonardo. Políticas públicas: conceitos, esquemas de análise, casos práticos. $2^{a}$ ed. São Paulo: Cengange Learning, 2015.

SERNA, Miguel. Reconversão democrática das esquerdas no Cone Sul: trajetórias e desafios na Argentina, Brasil e Uruguai. Bauru: EDUSC, 2004. 
Maré Rosa e agenda de políticas sociais:

as plataformas de governo do PSCh (2000) e PT (2002)

SILVA, Fabricio Pereira da. Vitórias na Crise: trajetórias das esquerdas latinoamericanas contemporâneas. Ponteio Edições. Rio de Janeiro. 2011.

WILENSKY, Harold. The Welfare State and Equality. Berkeley, University of California, 1975.

Recebido em 19/01/2018.

Aprovado em 19/05/2018. 
